\title{
Synthesis of Benzo [f] Quinoline and its Derivatives: Mini
}

\section{Review}

\author{
Dorina Amăriucăi-Mantu, Mangalagiu II and Antoci V* \\ Organic Chemistry Department, “Alexandru Ioan Cuza” University of Iasi, Romania \\ *Corresponding author: Vasilichia Antoci, Organic Chemistry Department, Faculty \\ of Chemistry, "Alexandru Ioan Cuza" University of Iasi, 11 Carol I Bd, 700506-Iasi, \\ Romania, Tel: +402322011022535; Email: vasilichia.antoci@uaic.ro
}

\section{Mini-Review \\ Volume 3 Issue 1}

Received Date: February 22, 2019

Published Date: March 18, 2019

DOI: $10.23880 /$ macij-16000133

\section{Abstract}

This study exhibit a short review looking the synthesis of benzo[f]quinoline and its derivatives, over the years. The described syntheses highlighted in this manuscript consist in the first Skraup synthesis presented in the literature by Clem and Hamilton, continuing with the photochemical cyclohydrogenation, provided by Loader and Timmons and with a Doebner-Von Miller reaction, reported by Ramann and Cowen.

Key words: Benzo[f]quinoline derivatives; Skraup reaction; Photochemical cyclohydrogenation; Heterocycloaddition

\section{Introduction}

Benzo[f]quinoline is an aza-polynuclear aromatic nitrogen heterocycle [1,2], showing a blue emitting fluorescence due to the $\pi-\pi$ extended conjugation [3]. Despite of the fact that this azaheterocycle has been detected in coal tar, cigarette smoke, petroleum distillate, urban air particulates having genetic effects, some of its derivatives were discovered to have biological properties, including antibacterial activity [4], anticancer activity [5], UDP (uridine diphosphate) glucuronosyltransferase activity [6], and also some analogues could be used as organic light-emitting devices (OLED) [7].

The synthesis of benzo[f]quinoline and its derivatives is a long study topic. Thus, in the literature are described different reactions for the syntheses of this nitrogen heterocycle and its analogues, like the Skraup reaction between anhydrous glycerol and nitro-substituted or non- substituted 2-naphtylamine [8,20], the photochemical cyclohydrogenation of some trans-2-stilbazole derivatives $[9,10]$, the $4+2$ cycloaddition of N(butyloxycarbonylmethylene)-p-toluene sulfonamide with 1-vinyl-6-methoxy-3,4-dihydronaphthalene [11], the Doebner-Von Miller reaction of 2-naphtylamine and 3,3diethoxyprop-1-ene and so on [21].

\section{Synthesis of Benzo[f]quinoline and its Derivatives}

\section{Synthesis of benzo[f]quinoline and its nitro- derivates}

One of the first syntheses of benzo[f]quinoline described in the literature (3a) (by a modification of Knueppel synthesis) and its 8-nitro- (3b) and 10-nitroderivatives (3c) are reported by Clem \& Hamilton [8] using a Skraup reaction (Figure 1). 


\section{Medicinal \& Analytical Chemistry International Journal}<smiles>[R3]c1cc([R])c2cc(N)ccc2c1</smiles>

$(1 \mathrm{a}-\mathrm{c})$<smiles>OCC(O)CO</smiles>

(2)

(1a, 3a) $\mathrm{R}_{1}, \mathrm{R}_{2}=\mathrm{H}$ (1b, 3b) $\mathrm{R}_{1}=\mathrm{NO}_{2}, \mathrm{R}_{2}=\mathrm{H}$

(ii) $\mathrm{H}_{3} \mathrm{BO}_{3} / \mathrm{FeSO}_{4}$ for $3 \mathbf{b}, \mathbf{c}$

列 3

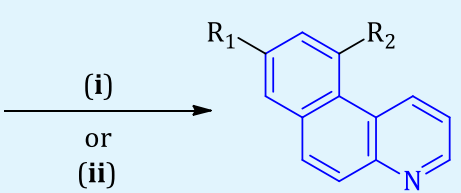

$(3 a-c)$ (1c, 3c) $\mathrm{R}_{1}=\mathrm{H}, \mathrm{R}_{2}=\mathrm{NO}_{2}$

Figure 1: Synthesis of benzo[f]quinoline (3a) and its nitro-derivates $(3 b, c)$.

In these reactions were used anhydrous glycerol (2), nitro-substituted and non-substituted 2-naphtylamines (1a-c) and a mixture of arsenic acid/sulfuric acid for synthesis of (3a), respectively ferrous sulfate/boric acid for $(3 b, c)$.

\section{Synthesis of Benzo[F]Quinoline Derivatives using Photochemical Cyclohydrogenation}

Loader \& Timmons [9] using photochemical cyclohydrogenation of trans-2-stilbazole (4a) and its derivatives $\alpha$-methyl- and 6-methyl-trans-2-stilbazole $(4 \mathrm{~b}, \mathrm{c})$, obtained benzo[f]quinoline (3a) and 5- and 3methylbenzo[f]quinolines $(5 \mathrm{~b}, \mathrm{c})$, respectively (Figure 2$)$.

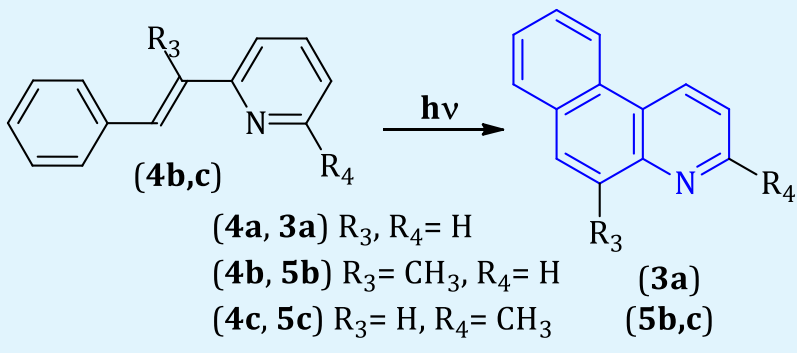

Figure 2: Photochemical cyclohydrogenation of trans-2-stilbazole (4a) and its methyl-derivates $(4 b, c)$.

These reactions had been done in cyclohexane under irradiation with a Hanovia 400w medium-pressure mercury-vapour lamp, until the disappearance of the absorption bands of azaphenanthrene. The benzo[f]quinoline (3a) and its derivatives (9b-d) were synthesized by Kumler \& Dybas [10] using oxidative photo cyclization of some trans-2-stilbazole derivatives (6a-d) (Figure 3).<smiles>[X]/C(=C\c1ccc([R])cn1)c1ccccc1[R]</smiles>

(4a, 6b-d)<smiles>[R]c1ccccc1/C=C\c1ccccc1</smiles>

(7a-d)<smiles>[R]C1C=CC=CC2C(C)C=CC(C)=CC12</smiles>

(8a-d)<smiles>[R]c1cnc2cc([X])c3c([R])cccc3c2c1</smiles>

(3a) (9b-d)

(a) $\mathrm{X}=\mathrm{H} ; \mathrm{R}, \mathrm{R}^{\prime}=\mathrm{H}$

(b) $\mathrm{X}=\mathrm{CN} ; \mathrm{R}, \mathrm{R}^{\prime}=\mathrm{H}$

(c) $\mathrm{X}=\mathrm{CN} ; \mathrm{R}=\mathrm{OCH}_{3} ; \mathrm{R}^{\prime}=\mathrm{H}$

(d) $\mathrm{X}=\mathrm{COOCH}_{3} ; \mathrm{R}, \mathrm{R}^{\prime}=\mathrm{H}$

Figure 3: Synthesis of benzo[f]quinolines $(3 a, 9 b-d)$ and the proposed mechanism. 


\section{Medicinal \& Analytical Chemistry International Journal}

In this study the authors presume that during the irradiation the trans-2-stilbazole derivative (6a-d) suffers a rapid trans-cis isomerization, getting the cis-2-stilbazole derivatives (7a-d). From cis-form through cyclization were obtained the dihydro-benzo[f]quinolines (8a-d), which by oxidative dehydrogenation gave the aromatized desired compounds (3a,9b-d).

\section{Synthesis of Benzo[f]quinoline Derivatives via Heterocycloaddition}

The synthesis of some aza-polynuclear systems are described in the literature, by using $4+2$ cycloaddition reaction. Thus, Zunnebeld \& Speckamp [11] obtained benzo[f]quinoline derivatives (13) via heterocycloaddition of $\mathrm{N}$-(butyloxycarbonylmethylene)p-toluene sulfonamide (10) with 1-vinyl-6-methoxy-3,4dihydronaphthalene (11) (Figure 4).

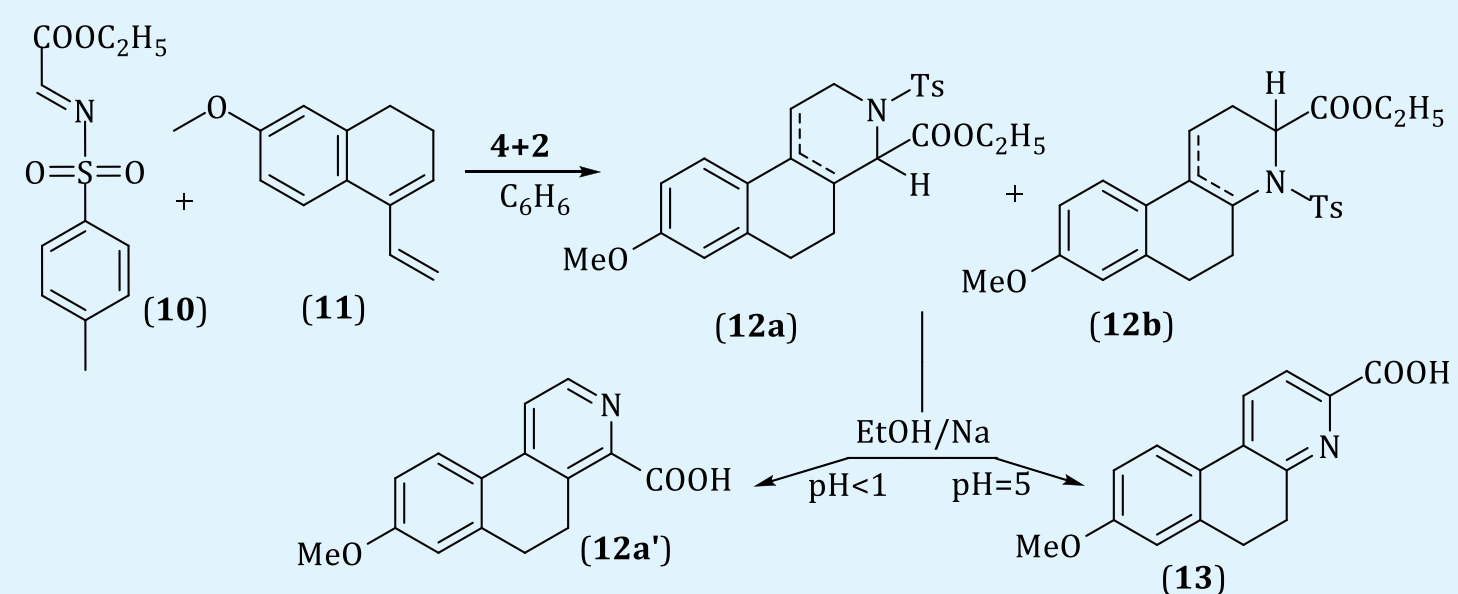

Figure 4: The 4+2 cycloaddition of N-(butyloxycarbonylmethylene)-p-toluene sulfonamide (10) with 1-vinyl-6methoxy-3,4-dihydronaphthalene (11).

From the $4+2$ cycloaddition was obtained a mixture of two adducts (12a) and (12b), whose separation has been achieved using sodium ethoxide in ethanol at different $\mathrm{pH}$ to afford the 4-carboxy-8-methoxydihydrobenzo[f]isoquinoline (12a') and benzo[f]quinoline (13), respectively. Also, Zunnebeld and Speckamp [11], using the dihydro compound (13) in esterification reactions, obtained the corresponding methyl and ethyl esters (14) and (15). The dehydrogenation reaction of dydidro compound (15) gave the benzo[f]quinoline derivative (17), which was converted into the acetate derivative (18), in a mixture of EtOAc/NaH in tetrahydrofuran (Figure 5). The dihydro-benzo[f]quinoline acetate (16) was obtained from ethyl ester derivative (14).

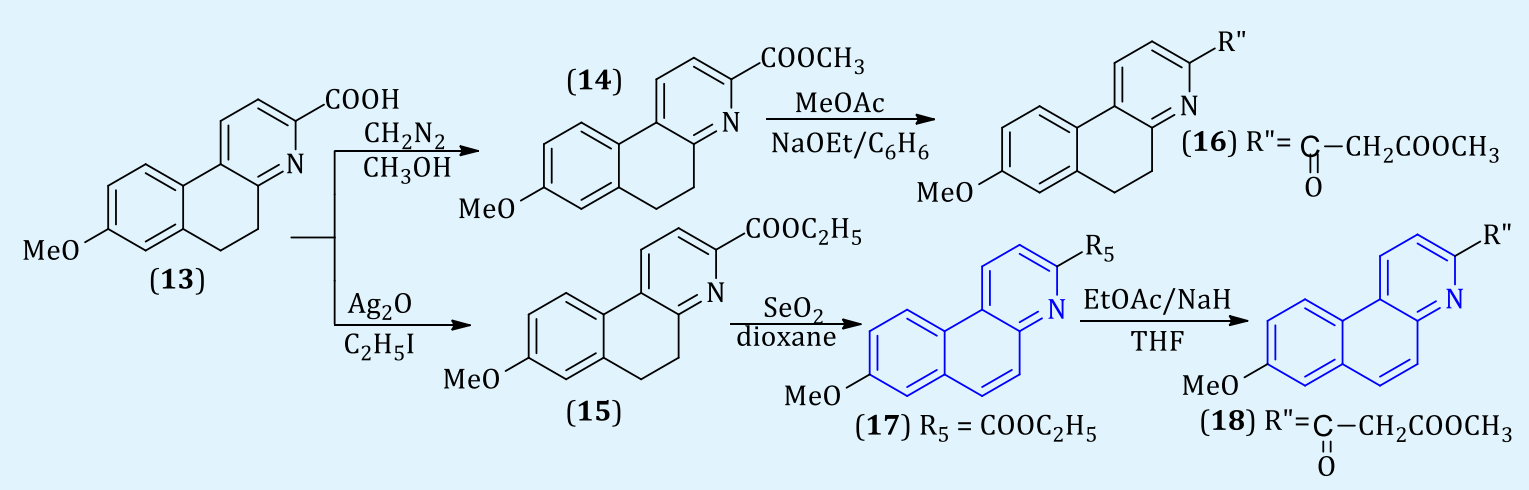

Figure 5: Synthesis of dihydro-benzo[f]quinoline derivatives (14-16) and the aromatized benzo[f]quinoline compounds $(17,18)$. 


\section{Medicinal \& Analytical Chemistry International Journal}

\section{Synthesis of Methylbenzo[f]quinolines and Methyl-N-oxidebenzo[f]quinolines}

The methyl-benzo[f]quinoline derivatives (5b) and (19) were reported in the literature by Hamada \& Takeuchi [12], using the methylation reaction between benzo[f]quinoline (3a) and methylsulfinyl carbanion, generated from dimethylsulfoxide with sodium hydride (Figure 6). The 6-methyl compound (19), was also synthesized by a Skraup reaction, starting from anhydrous glycerol (2), a mixture of acids (Sulfo-mix) and 4-methyl-2-naphtylamine (1d) [13].<smiles>c1ccc2c(c1)ccc1ncccc12</smiles>

(3a)

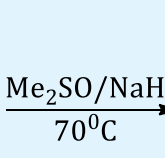<smiles>Cc1cc2cccnc2cc1C</smiles>

(19) $(37 \%)$<smiles>Cc1cc(N)cc2c(C(O)CO)cccc12</smiles>

Figure 6: Synthesis of methyl-benzo[f]quinoline derivatives (5b) and (19).

From the methylation reaction of Noxidebenzo[f]quinoline (20) with methylsulfinyl carbanion, generated like above, the autors, isolated only the phenanthrene (21). Using other method to generate the methylsulfinyl carbanion (from tert-BuOK and dimethylsulfoxide), was obtained the 3methylbenzo[f]quinoline-4-oxide (22) and a deoxygenated product, 3-methylbenzo[f]quinoline (5c) (Figure 7).

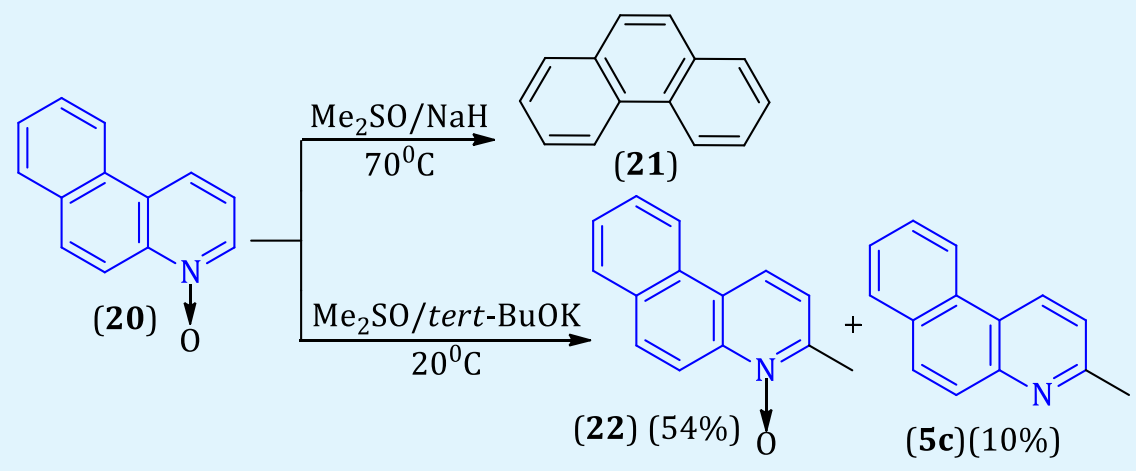

Figure 7: The reaction of $\mathrm{N}$-oxidebenzo[f]quinoline (20) with methylsulfinyl carbanion.

\section{Synthesis of Benzo[f]quinoline-5,6-oxide}

Kitahara, et al. [14] have performed the oxidation reaction of benzo[f]quinoline (3a) in order to synthesize the benzo[f]quinoline-5,6-oxide (23). Thus, using ozone in methanol at low temperature they obtained the dialdehyde derivative (23a), which with tris (dimethyamino) phosphine leaded to the formation of desired oxirane ring (Figure 8). 


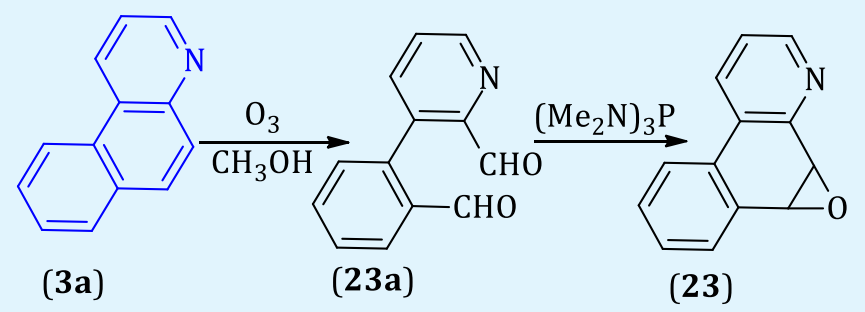

Figure 8: Synthesis of benzo[f]quinoline-5,6-oxide (23).

The researchers also studied some reactions of benzo[f]quinoline-5,6-oxide(23). Thereby, the isomerization reaction of (23) with trifluoroacetic acid or $24 \%$ hydro bromic acid gave quantitatively 5- hydroxybenzo[f]quinoline (24). Instead, using 35\% hydrochloric acid, was isolated the hydroxy chloride derivative (25), which heated in pyridine gave 5hydroxybenzo[f]quinoline (24) in a good yield (Figure 9).

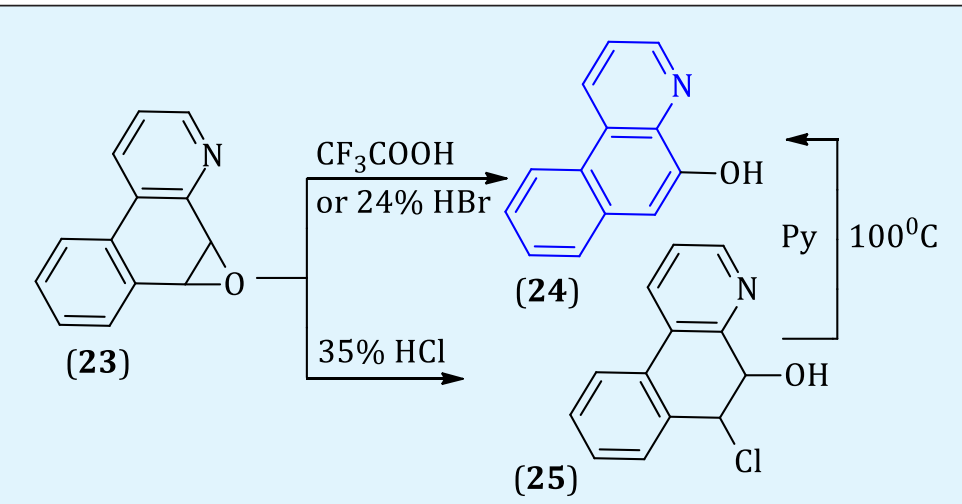

Figure 9: The reactions of benzo[f]quinoline-5,6-oxide (23).

\section{Synthesis of Fluorinated Benzo[f]quinoline Derivatives}

The fluorinated benzo[f]quinoline derivatives (26a-d, $27,28)$ were reported by Saeki, et al. [15], using the Schiemann reaction or by an electrolytic method. The
Schiemann reaction consisted in treating the corresponding aromatic amines (26a'-d') with isoamyle nitrite and HBF4, to give 2-, 3-, 7- and 10fluorobenzo[f]quinoline (26a-d) (Figure 10).<smiles></smiles>

(26a') $\mathrm{R}_{7}=\mathrm{NH}_{2} ; \mathrm{R}_{6,8,9}=\mathrm{H}$

(26b') $\mathrm{R}_{6}=\mathrm{NH}_{2} ; \mathrm{R}_{7,8,9}=\mathrm{H}$

(26c') $\mathrm{R}_{9}=\mathrm{NH}_{2} ; \mathrm{R}_{6,7,8}=\mathrm{H}$

(26d') $\mathrm{R}_{8}=\mathrm{NH}_{2} ; \mathrm{R}_{6,7,9}=\mathrm{H}$

Figure 10: Synthesis of 2-, 3-, 7-, 10-fluorobenzo[flquinoline (26a-d). 
Also, by electrochemical fluorination (EF) of benzo[f]qunoline (3a) with $\mathrm{Bu} 4 \mathrm{~N} \bullet 4.45 \mathrm{HF}$ at a constant voltage $(2.7 \mathrm{~V})$, the authors obtained the di- and tetra- fluorobenzo[f]quinoline derivatives (27) and (28) (Figure 11).<smiles>c1ccc2c(c1)ccc1ncccc12</smiles>

(3a)<smiles>Fc1ccc(F)c2c1ccc1ncccc12</smiles>

(27)<smiles>FC1(F)C=CC(F)(F)c2c1ccc1ncccc21</smiles>

(28)

Figure 11: Electro fluorination of benzo[f]quinoline (3a).

\section{Synthesis of a Series of Benzo[f]quinolines via a Reaction of Schiff Bases with 1,3-dicarbonyl}

Wang, et al. [16] have reported an efficient method for the synthesis of a series of benzo[f]quinolines (31a-e) via the reaction of Schiff bases with 1,3-dicarbonyl compounds in aqueous medium catalyzed by TEBA (benzyltriethylammonium chloride). Thus, by the reaction between $\mathrm{N}$-arylidenenaphthalen-2-amines (29a-e) and 2,2-dimethyl-1,3-dioxane-4,6-dione (30) in $\mathrm{H}_{2} \mathrm{O}$ with TEBA, the expected compounds (31'a-e) were not isolated, but, through a Michael addition, were obtained the benzo[f]quinoline derivatives (31a-e) and small amounts of byproducts (32a-e) (Figure 12).

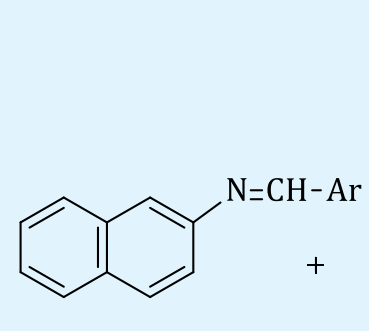

(29a-e)

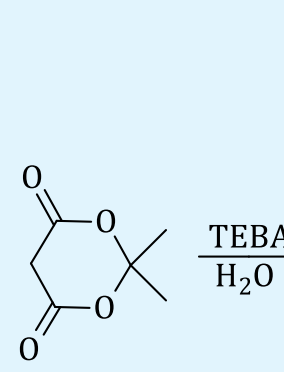

(30)

(a) $\mathrm{Ar}=4-\mathrm{ClC}_{6} \mathrm{H}_{4} ;$ (b) $\mathrm{Ar}=4-\mathrm{BrC}_{6} \mathrm{H}_{4}$

(c) $\mathrm{Ar}=2-\mathrm{ClC}_{6} \mathrm{H}_{4}$; (d) $\mathrm{Ar}=3,4-\mathrm{Cl}_{2} \mathrm{C}_{6} \mathrm{H}_{3}$

(e) $\mathrm{Ar}=4$-Thiophenyl<smiles>C#CC1C2=C(Nc3ccc4ccccc4c31)OC(C)(C#C)OC2=O</smiles>

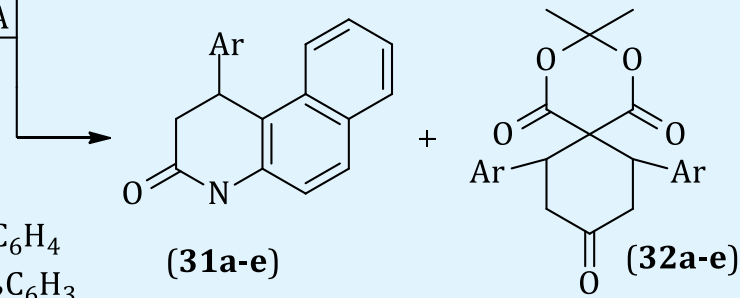

Figure 12: Synthesis of a series of benzo[f] quinoline derivatives (31a-e).

\section{Synthesis of Benzo[f]quinoline Derivatives using a Three-Component Reaction}

Wang, et al. [17] presented in literature an efficient method for getting of benzo[f]quinoline derivatives (33ad) in good yields. Thus, three-component reaction of arenecarbaldehydes (34a-d), naphthalen-2-amine (1a) and acyclic ketones (35a-d), catalyzed by iodine in THF, have led to generation of expected benzo[f]quinolines (33a-d) (Figure 13). 


$$
\begin{aligned}
& \mathrm{Ar}-\mathrm{CH}=\mathrm{O}+ \\
& \text { (34a-d) (1a) (35a-d) } \\
& \text { (33a-d) }
\end{aligned}
$$

Figure 13: The three-component reaction for the synthesis of benzo[f]quinolines (33a-d).

\section{Synthesis of Benzo[f]quinolines using a Suzuki Coupling and a Cyclization Reaction}

The synthesis of benzo[f]quinoline (3a) and its analogue (36) are described by Mamane, et al. [18] using a two-step sequence. The first step was a cross-coupling Suzuki reaction between pyridines $(37 \mathrm{a}, \mathrm{b})$ and boronic acids $(38 \mathrm{a}, \mathrm{b})$, in toluene with Pd (PPh3)4, as catalyst, with the generation of aromatic aldehydes (39a,b) (Figure 14). The aromatic aldehydes $(39 a, b)$ have suffered, in the second step, a cyclization reaction with potassium tertbutoxide in dimethylformamide, to delivered the benzo[f]quinolines (3a) and (36).

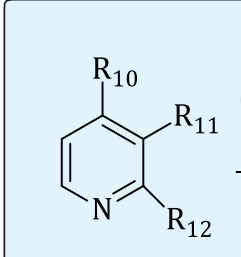

$(37 a, b)$

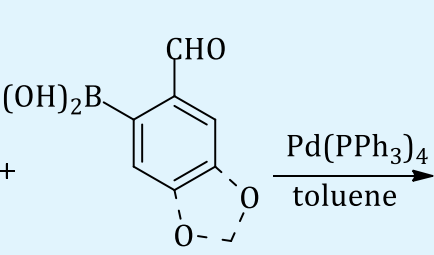

$(38 a, b)$

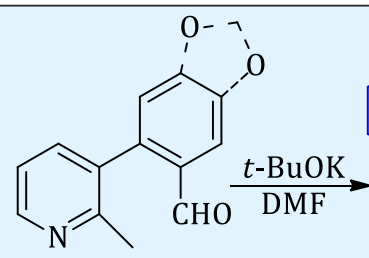

$(39 a, b)$<smiles></smiles>

(3a)<smiles></smiles>

(36)

(37a) $\mathrm{R}_{10}=\mathrm{H}, \mathrm{R}_{11}=\mathrm{OT}_{\mathrm{f}}, \mathrm{R}_{12}=\mathrm{CH}_{3}$

(37b) $\mathrm{R}_{10}=\mathrm{CH}_{3}, \mathrm{R}_{11}=\mathrm{Br}, \mathrm{R}_{12}=\mathrm{H}$

Figure 14: The two-step sequence for the synthesis of benzo[f]quinoline (3a) and its analogue (36).

\section{Synthesis of Benzo[f]quinolines by Direct Lithiation of the Pyridine Ring}

The first direct lithiation of the pyridine ring of benzo[f]quinoline was reported in the literature by Mamane, et al. [19]. Thus, using the superbase $n$-BuLiLiDMAE

lithium dimethylaminoethanolate), in a nonpolar solvent (toluene), and hexachloroethane $\left(\mathrm{C}_{2} \mathrm{Cl}_{6}\right)$, tetrabromomethane $\left(\mathrm{CBr}_{4}\right)$ or 1,2-diphenyldisulfane ( $\mathrm{PhSSPh}$ ) as electrophiles, in THF, followed by hydrolysis, afforded in good yields the benzo[f]quinoline derivatives (40a-c) (Figure 15).<smiles>c1ccc2c(c1)ccc1ncccc12</smiles>

(3a)

(Electrophiles: $\mathrm{C}_{2} \mathrm{Cl}_{6}, \mathrm{CBr}_{4}, \mathrm{PhSSPh}$ ) 3) $\mathrm{H}_{2} \mathrm{O}$
1) n-BuLi-LiDMAE/toluene $\left(-78^{0} \mathrm{C}\right)$

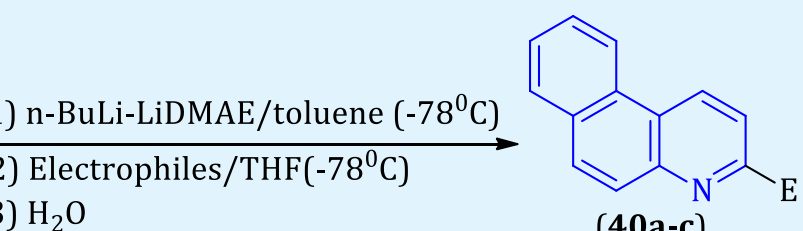

(40a-c) (a) $\mathrm{E}=\mathrm{Cl}(92 \%) ;($ b) $\mathrm{E}=\mathrm{Br}(68 \%)$

(c) $\mathrm{E}=\mathrm{SPh}(74 \%)$

Figure 15: Synthesis of some 3-substituted benzo[f]quinolines (40a-c) by direct lithiation. 
Also, by the reaction between benzo[f]quinoline (3a) and different bases n-BuLi, MeLi (methyllithium) or PhLi (phenyllithium) and DME (dimethoxyethane), the authors, isolated the desired alkyl-benzo[f]quinolines (41a-c) (Figure 16).<smiles>c1ccc2c(c1)ccc1ncccc12</smiles>

(3a)

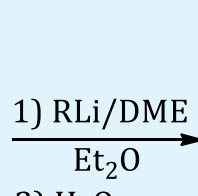

2) $\mathrm{H}_{2} \mathrm{O}$<smiles>[R]c1ccc2c(ccc3ccccc32)n1</smiles>

(41a-c)

(b) $\mathrm{R}=\mathrm{Me}(65 \%)$

(c) $\mathrm{R}=\mathrm{Ph}(91 \%)$

Figure 16: Synthesis of the alkyl-benzo[f]quinolines (41a-c).

\section{Synthesis of Benzo[f]quinoline and} Hydrochloride Derivative via a Skraup Reaction

In order to improve the previous reported method in the literature, Bejan \& Mangalagiu [20] have synthesized benzo[f]quinoline (3a) via a Skraup reaction using a mixture of 2-naphtylamine (1a), anhydrous glycerol (2), concentrated sulfuric acid and arsenic acid (Figure 17).<smiles>Nc1ccc2ccccc2c1</smiles>

(1a)
(2)

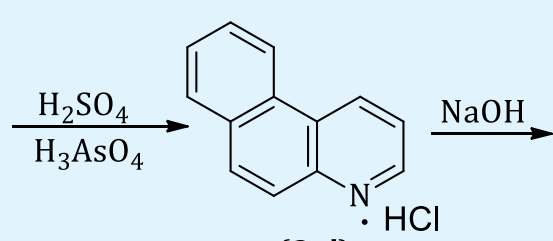

(3a')<smiles>c1ccc2c(c1)ccc1ncccc12</smiles>

(3a)

Figure 17: Synthesis of benzo[f]quinoline hydrochloride (3a') and benzo[f]quinoline (3a).

In this reaction was isolated and characterized the benzo[f]quinoline hydrochloride (3a'), then the free base (3a) (obtained by neutralization with sodium hydroxide $6 \mathrm{~N}$ ), which was subsequently purified using flash chromatography. Also, a detailed spectral characterization has been performed (NMR experiments, MS).

\section{Synthesis of Benzo[f]quinoline using the Doebner-Von Miller Reaction}

The synthesis of benzo[f]quinoline (3a) in a good yield is presented by Ramann \& Cowen [21], using a DoebnerVon Miller reaction between 2-naphtylamine (1a) and 3,3diethoxyprop-1-ene (41), cyclization being accomplished with a solution of $1 \mathrm{~N}$ hydrochloric acid (Figure 18).<smiles>Nc1ccc2ccccc2c1</smiles>

(1a)<smiles>C=CC(OCC)OCC</smiles>

(41)

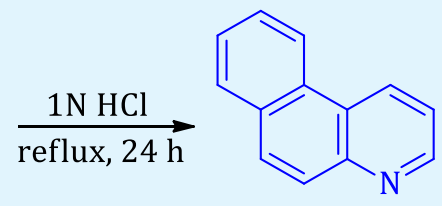

(3a)

Figure 18: Synthesis of benzo[f]quinoline (3a) using the Doebner-Von Miller reaction. 


\section{Medicinal \& Analytical Chemistry International Journal}

\section{Conclusion}

The synthesis of benzo[f]quinoline and its nitro-, methyl-, alkyl-, fluoro-, aromatic-substituted derivatives, in satisfactory yields is reported. These syntheses consisted of Skraup reaction, oxidation reaction, a threecomponent reaction, Suzuki coupling followed by a cyclization reaction, direct lithiation reaction of the pyridine ring, Doebner-Von Miller reaction and other.

\section{References}

1. Sikka HC, Kandaswamia C, Kumar S, Rutkowski JP, Dubey SK, et al. (1988) Hepatic DNA adduct formation in rats treated with benzo[f]quinoline. Cancer Lett 43(1-2): 133-138.

2. Wiseman A, Sims LA, Snead R, Gronert S, Maclagan R, et al. (2015) Protonation Energies of 1-5-Ring Polycyclic Aromatic Nitrogen Heterocyclics: Comparing Experiment and Theory. J Phys Chem A 119(1): 118-126.

3. Goel A, Kumar V, Singh SP, Sharma A, Prakash S, et al. (2012) Non-aggregating solvatochromic bipolar benzo[f]quinolines and benzo[ $a]$ acridines for organic electronics. J Mater Chem 22(30): 14880-14888.

4. Bahuguna RP, Joshi BC, Mangal HN (1992) Studies on benzoquinoline derivatives: preparation and antimicrobial activityof azo-derivatives of arylthiobenzo[f]quinoline. J Indian Chem Soc 69(7): 401-402.

5. Monge A, Alvarez E, San Martín C, Nadal E, Ruiz I, et al. (1997) Synthesis and evaluation of new Reissert analogs as HIV-1 RT inhibitors. 2. Benzo[f]quinoline and pyridine derivatives. Drug Des Discov 14(4): 291303.

6. Le HT, Lamb JG, Franklin MR (1996) Drug metabolizing enzyme induction by benzoquinolines, acridine, and quinacrine; tricyclic aromatic molecules containing a single heterocyclic nitrogen. J Biochem Toxicol 11(6): 297-303.

7. Yang S, Hua W, Wu Y, Hu T, Wang F, et al. (2018) Siteselective Synthesis of Functionalized Dibenzo[f,h]quinolines and their derivatives involving cyclic diaryliodonium salts via Decarboxylative Annulation Strategy. Chem Comm 54(26): 3239-3242.

Antoci V, et al. Synthesis of Benzo [f] Quinoline and its Derivatives: Mini Review. Med \& Analy Chem Int J 2019, 3(1): 000133.
8. Clem WJ, Hamilton CS (1940) Nitro and Aminobenzo [f]quinolines and Derivatives. J Am Chem Soc 62(9): 2349-2352.

9. Loader CE, Timmons CJ (1966) Studies in Pthochemistry. Part II. The Photocyclisation of Stilbazoles to Azaphenanthrenes. J Chem Soc (C): 1078-1081.

10. Kulmer PL, Dybas RA (1970) Photochemical Cyclizations. I. Preparation of Benzo[f]quinolines by Photolisis of 2-Stilbazole Derivatives. JOC 35(1): 125131.

11. Zunnebeld WA, Speckamp WN (1975) Total Synthesis of 13- and 14-Azaequilenines via Heterocycloaddition. Tetrahedron 31(15): 17171721.

12. Hamada Y, Takueki I (1977) Syntheses of NitrogenContaining Heterocyclic Compounds. 26. Reaction of Benzo $[f$ or $h]$ quinolines and Their N-oxides with Methylsulfinyl Carbanion. J Org Chem 42(26): 42094213.

13. Utermohlen WP Jr (1943) Improved Syntheses of Quinaldines and 3-Alkyl quinolines. J Org Chem 8(6): 544-549.

14. Kitahara Y, Shudo K, Okamoto T (1977) Synthesis and some reactions of benzo[f]quinoline 5,6-oxide. Heterocycles 8: 363-366.

15. Saeki K, Tomomitsu M, Kawazoe Y, Momota K, Kimoto $\mathrm{H}$ (1996) Fluorinated Benzo[h]quinolines and Benzo[f]quinolines. Chem Pgarm Bull 44(12): 22542258.

16. Wang XS, Zhang MM, Zeng ZS, Shi DQ, Tu SJ, et al. (2005) A simple and clean procedure for the synthesis of polyhydroacridine and quinoline derivatives: reaction of Schiff base with 1,3dicarbonyl compounds in aqueous medium. Tetrahedron Lett 46(42): 7169-7173.

17. Wang XS, Li Q, Yao CS, Tu SJ (2008) An Efficient Method for the Synthesis of Benzo[f]quinoline and Benzo[a]phenanthridine Derivatives Catalyzed by Iodine by a Three-Component Reaction of Arenecarbaldehyde, Naphthalen-2-amine, and Cyclic Ketone. Eur J Org Chem 2008(20): 3513-3518.

18. Mamane V, Louërat F, Iehl J, Abboud M, Fort Y (2008) A general and efficient method for the synthesis of 


\section{Medicinal \& Analytical Chemistry International Journal}

benzo-(iso)quinoline derivatives. Tetrahedron 64(47): 10699-10705.

19. Mamane V, Louërat F, Fort Y (2010) Direct Functionalization of Benzoquinolines. Lett Org Chem 7(1): 90-93.

20. Bejan V, Mangalagiu II (2011) Benzo[f]quinoline: Synthesis and Structural Analysis. Rev Chim (Bucharest) 62(2): 199-200.
21. Ramann GA, Cowen BJ (2015) Quinoline synthesis by improved Skraup-Doebner-Von Miller reactions utilizing acrolein diethyl acetal. Tetrahedron Lett 56(46): 6436-6439. 